\title{
Combination of Candlestick Pattern and Stochastic to Detect Trend Reversal in Forex Market
}

\author{
Agustinus Noertjahyana \\ Informatics Department \\ Petra Christian University \\ Surabaya, Indonesia \\ agust@petra.ac.id
}

\author{
Agustinus Noertjahyana, Zuraida Abal Abas, Zeratul \\ Izzah Mohd Yusoh \\ Faculty of Information and Communication Technology \\ Universiti Teknikal Malaysia Melaka \\ Melaka, Malaysia
}

\begin{abstract}
A variety of ways traders do to determine the decision to buy/sell on the forex market. It bases one that is popular on candle patterns. Some strategies that use candle patterns include: pin bar, engulfing, and inside the bar. But the strategy used is still limited to determining buying/selling decisions. This research will use a combination of candle pattern strategies and stochastic moving average to determine the level of risk that exists in each buy/sell decision on the forex market. By using this combination, the results are good in Eur/USD pairs.
\end{abstract}

Keywords-Candlestick Pattern; Combination Method; Forex Prediction

\section{INTRODUCTION}

Candlestick patterns are one concept of trading that is accurate, simple, easily identified, and profitable. confirm that the candlestick pattern has a high predictive value and can produce positive results. Many traders make buying/selling transactions on the forex market using the candle pattern method. In Japanese candlesticks, there are several kinds of candle patterns to support the trend that is a reversal or continue [1], but often a candle pattern is formed which should be a reversal trend to continue or vice versa. A trader needs to combine with other methods to better find out whether the trend on the candle reversal or continue. In technical analysis, many researchers conduct research by only looking at the level of benefits that can be obtained when using certain methods, but few researchers by measuring the level of risk got per transaction.

Based on our method, this article develops a trading system method by using a candle pattern to look for trend changes while measuring the level of risk that occurs in each transaction.

This developed we have tested system on one of the main forex pairs, Eur / USD. As a result, this method can provide alternative benefits to traders who use candlestick patterns in decision making.

\section{BACKGROUND}

Trading on the forex market has considerable challenges, where trading volatility is high and the range of price movements is large enough every day. Traders who make transactions often always look at the chart continuously for fear of loss because of not understanding the level of risk when making transactions. Although there are several methods to determine stop loss based on technical indicators, it is still a matter of debate because there is no correct and accurate method that can beat the market because prices can change randomly and move quickly [2].

Because the stock market and the forex market have high similarities, we can use the technical indicators used in the stock market in the forex market, although there are some adjustments [3]. Some methods are suitable for the stock market but are less successful when implemented in the forex market.

Several studies [4][5] have found methods that can be implemented in trading rules, which analyze the Dow-Jones index. Some authors use a computational intelligence approach to design and develop technical trading strategies such as genetic algorithms, neural networks, fuzzy logic and data mining[6].

[7][8] used genetic algorithms to study the rules of technical trade and they found that the rules did not get significant benefits. [9] combines simple technical methods and neural networks to gain nonlinear profitability and predictability on the stock market. [10] propose a method for designing and testing stock market trading systems using artificial neural networks. And some Fuzzy Logic which specifically allows a significant increase in the financial analysis [11][12]. We can find fuzzy controls on trade-in [5] and [13]. All the methods above forecast, but it is not a decision to make a transaction.

In the last few decades, several interesting uses of Japanese candlesticks have appeared. [14] applies an expert system with IF-THEN rules that detect candle patterns and offer to sell and buy decisions, with a good ratio on the Korean market.

\section{METHODOLOGY}

This paper assists traders in making decisions to buy/sell transactions based on candlestick patterns and determine the level of risk of each transaction based on a reversal candle. This reversal candle is a candle that is the opposite of the previous candle and the close position is bigger or smaller than the previous candle. We will combine this method with the Stochastic method based on the Simple Moving Average. 


\section{A. Candlestick Pattern Selection}

Candlestick charts require four fundamental price data (open, high, low, and close) to arrange a chart, just like a bar chart. However, candle charts are easier to understand than bar charts. We believe that one or more candle patterns can describe market conditions and emotions [1]. We can see candlestick charts in Fig 1.

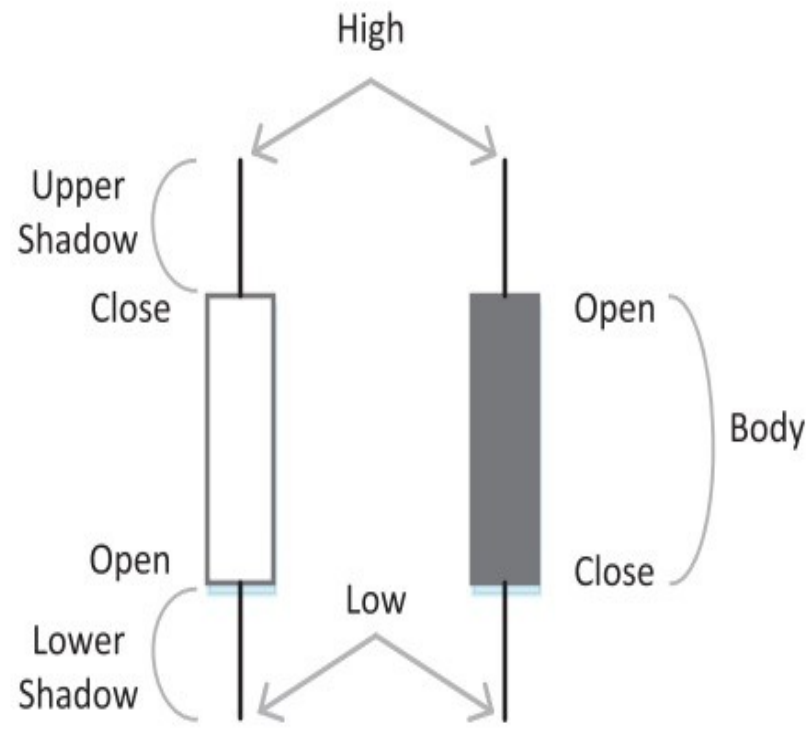

Fig. 1. Candlestick Chart

First, we must look at the T-1 candle. If T- 1 is a Bullish Candle, is the Close Candle T-1 higher than the High Candle $\mathrm{T}-2$. If T-1 is a Bearish Candle, is the Close Candle T-1 lower than the Low Candle T-2. Example, See Fig. 2. Bullish Candle is described as an empty box, while we describe the Bearish Candle as a black square. Stop Loss uses the open limit if the T candle is a Bearish candle, while the Stop Loss uses the Close limit if the $\mathrm{T}$ candle is a Bullish candle. We expect it to minimize the risk of loss if an error occurs in the decision to buy/sell.

\section{B. Compare with Stochastic}

Second, compare with Stochastic.

If the T-1 Candle is a Bearish Candle, then observe whether the Stochastic is between 20-100, and if the T-1 Candle is a Bullish Candle, then observe whether the Stochastic is in the 080 range

\section{If-Then Rules}

The implemented rules are:

If the T-1 Bearish Candle and Stochastic are between 20100 , then the decision is Sell and if the T-1 Bullish Candle and Stochastic are between 0-80, then the decision is Buy.
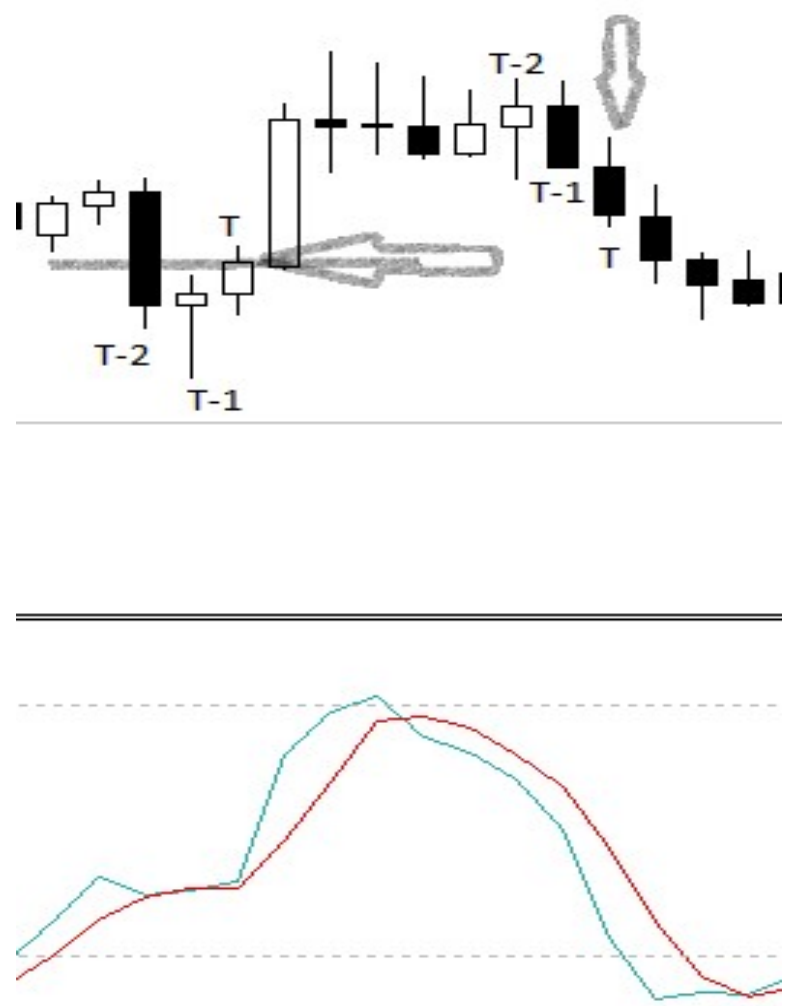

Fig. 2. Example of Bearish and Bullish Candle

\section{RESULT AND DISCUSSION}

To test the method, we use pair Eur/USD in the period of 1 January 2018 to 31 December 2018. Using the MetaTrader 4 software, we tested it with 2 scenarios. The first scenario is to set Profit at 30 pips and Stop Loss under Candle T-1, and the second scenario is to set Profit at 35 pips and Stop Loss under Candle T-1. We can see the results of the test in table 1 .

TABLE I. TRANSACTION RESULT

\begin{tabular}{|c|c|c|c|c|}
\hline Type & Total & Target Profit & Win(pips) & Loss(pips) \\
\hline Buy & 35 & 30 & 1950 & 1094 \\
\hline Sell & 45 & 35 & 2135 & 1347 \\
\hline
\end{tabular}

Based on Table 1, that during 1 year of trading testing there were more Sell decisions than Buy, where if a trader uses a 30 pips Profit Target, then the trader will get a profit ratio of around $64 \%$, whereas if using a 35 pips Profit Target, the trader will get a percentage of profits off around $61 \%$.

The total profit that can be obtained in the form of value if the trader uses a 30 pips Profit Target is $\$ 856$ (with 1 pips $=$ $\$ 1)$. Whereas if a trader uses a 35 pips Profit Target will get a profit of $\$ 788$ (with 1 pip $=\$ 1$ ) Based on Table 1, that during 1 year of trading testing there were more Sell decisions than Buy, where if a trader uses a 30 pips Profit Target, then the trader 
will get a profit ratio of around $64 \%$, whereas if using a 35 pips Profit Target, the trader will get a percentage of profits off around $61 \%$.

\section{CONCLUSION AND FUTURE WORK}

Based on testing that has been done, we can conclude it that using only the combination of candlestick and stochastic methods can produce a profit for a trader. The next research will be to minimize losses by using Fuzzy logic as a reference to determine the rules on the risk of loss so it can further minimize losses if there are errors in decision making.

\section{ACKNOWLEDGMENT (Heading 5)}

The Directorate General of Higher Education Indonesia sponsored this research project on the scheme "Penelitian Terapan Unggulan Perguruan Tinggi" in 2019. Many thanks to the Center of Research, Petra Christian University, Surabaya, Indonesia for the great wonderful piece.

\section{REFERENCES}

[1] [1] S. Nison, Japanese Candlestick. 2001.

[2] [2] E. F.Fama, "Efficient Capital Markets: A Review Of Theory And Empirical Work," J. Finance, vol. 25, no. 2, pp. 383-417, 1970.

[3] [3] K. K. Ludmila Dymova, Pavel Sevastjanov, "A Forex trading expert system based on a new approach.pdf," Expert Systems With Applications, vol. 51.pp. 1-13, 2016.
[4] [4] J. Baruník, E. Kočenda, and L. Vácha, "Asymmetric volatility connectedness on the forex market," J. Int. Money Financ., vol. 77, pp. 39-56, 2017.

[5] [5] R. Naranjo, A. Meco, J. Arroyo, and M. Santos, "An intelligent trading system with fuzzy rules and fuzzy capital management," Int. J. Intell. Syst., 2015.

[6] [6] Y. Lee, L. C. O. Tiong, and D. C. L. Ngo, "Hidden Markoy Models for Forex Trends Prediction," in 2014 International Conference on Information Science \& Applications (ICISA), 2014, pp. 1-4.

[7] [7] X. Liu, H. An, L. Wang, and X. Jia, "An integrated approach to optimize moving average rules in the EUA futures market based on particle swarm optimization and genetic algorithms," Appl. Energy, vol. 185, pp. 1778-1787, Jan. 2017.

[8] [8] R. Naranjo, J. Arroyo, and M. Santos, "Fuzzy modeling of stock trading with fuzzy candlesticks," Expert Syst. Appl., vol. 93, pp. 15-27, Mar. 2018.

[9] [9] N. Gradojevic and R. Gençay, "Fuzzy logic, trading uncertainty and technical trading," J. Bank. Financ., vol. 37, no. 2, pp. 578-586, Feb. 2013.

[10] [10] B. Vanstone and G. Finnie, "Enhancing stockmarket trading performance with ANNs," Expert Syst. Appl., vol. 37, no. 9, pp. 66026610, 2010.

[11] [11] P. Puhakainen et al., "InfoSec Reading Room," Inf. Secur., 2015.

[12] [12] R. M. L. G. and J. J. C., "A multiple fuzzy inference systems framework for daily stock trading with application to NASDAQ stock exchange," Expert Syst. Appl., vol. 44, no. C, pp. 13-21, Feb. 2016.

[13] [13] X. Liu, H. An, L. Wang, and Q. Guan, "Quantified moving average strategy of crude oil futures market based on fuzzy logic rules and genetic algorithms," Phys. A Stat. Mech. its Appl., vol. 482, pp. 444 457, Sep. 2017.

[14] [14] Y. Izumi, T. Yamaguchi, S. Mabu, K. Hirasawa, and Jingle Hu, "Trading Rules on the Stock Markets using Genetic Network Programming with Candlestick Chart," in 2006 IEEE International Conference on Evolutionary Computation, pp. 2362-2367. 